\title{
Clonal cytogenetic progression within intratumorally heterogeneous meningiomas predicts tumor recurrence
}

\author{
STEFFI URBSCHAT $^{1 *}$, JÖRG RAHNENFÜHRER ${ }^{5 *}$, WOLFRAM HENN ${ }^{2}$, WOLFGANG FEIDEN $^{3}$, \\ SILKE WEMMERT ${ }^{4}$, STEFAN LINSLER ${ }^{1}$, KLAUS D. ZANG $^{2}$, JOACHIM OERTEL ${ }^{1}$ and RALF KETTER ${ }^{1}$ \\ ${ }^{1}$ Department of Neurosurgery, ${ }^{2}$ Institute of Human Genetics, and ${ }^{3}$ Institute of Neuropathology, \\ ${ }^{4}$ Department of Otorhinolaryngology, Saarland University, D-66421 Homburg/Saar; \\ ${ }^{5}$ Faculty of Statistics, TU Dortmund University, D-44221 Dortmund, Germany
}

Received June 10, 2011; Accepted July 14, 2011

DOI: $10.3892 /$ ijo.2011.1199

\begin{abstract}
Meningiomas arise from the coverings of the brain or the spinal cord. They are mostly benign and can be surgically cured. However, in approximately $5 \%$ of the cases, they turn into malignant forms with aggressive clinical behavior and increased risk of tumor recurrence. Cytogenetically meningiomas are well characterized, with normal karyotype or monosomy of chromosome 22 in most tumors and clinically relevant secondary losses of other autosomes and sex chromosomes in a subset of anaplastic tumors. Statistical analyses were performed for 1064 karyotypes derived from 661 meningiomas with respect to progression, and recurrence of the tumor. The order of accumulating genetic aberrations has previously been biostatistically estimated with oncogenetic tree models, and a genetic progression score derived from these models was shown to be predictive for tumor recurrence. Although more homogeneous than other cancer types, meningiomas show considerable intratumoral cytogenetic heterogeneity, particularly in their anaplastic form. We observed different cytogenetic patterns in tumor cells of 224 out of 661 (33.4\%) meningiomas. The present study demonstrates that it is not sufficient to consider only the most frequent cytogenetic pattern observed in a sufficient set of cells derived from the same tumor. Even a single cell with more advanced genetic progression may start a clone and indicates also clinical progression. Cox regression analysis reveals that the clone with most advanced
\end{abstract}

Correspondence to: Dr Ralf Ketter, Universitätsklinikum des Saarlandes, Klinik für Neurochiorurgie, Gebäude 90.5, D-66421 Homburg/Saar, Germany

E-mail: ralf.ketter@uks.eu

*Contributed equally

Abbreviations: CT, computer tomography; EM, expectation maximization; GPS, genetic progression score; HE, hematoxylin-eosin stain; iFISH, interphase fluorescence in situ hybridization; NMR, magnetic resonance imaging; SD, standard deviation; WHO, World Health Organization

Key words: meningioma, intratumoral heterogeneity, chromosomes, genetic progression progression is a leading marker for recurrence in meningiomas. The aim of this study was the analysis of genetic heterogeneity on single cell basis. Further we investigated if there is a substantial correlation between the intratumoral heterogeneity of a given meningioma and its recurrence risk. We were able to show that the selection of single genetically advanced cells improves the prediction of clinical meningioma progression in a more precise manner.

\section{Introduction}

Meningiomas are almost always sporadic and rarely multiple tumors of the brain (1). In their sporadic form, they are typically benign and grow slowly. They appear mostly in the later decades of life. According to a study comprising 661 tumors (2), more than $75 \%$ of meningiomas belong to the common type (WHO grade I), $\sim 20 \%$ belong to the atypical or intermediate type (WHO grade II) and only $\sim 3 \%$ belong to the anaplastic type (WHO grade III). Anaplastic meningiomas and a minority of common and intermediate type meningiomas are characterized by aggressive clinical behavior with increased risk of tumor recurrence. However, meningiomas show an unexpectedly high recurrence rate (3-15).

Between 30 and $60 \%$ of meningiomas have a normal karyotype within the tumor cells. Loss of one chromosome 22 is known to be a primary event, but it is difficult to provide evidence for the homozygous loss of a tumor suppressor gene on this chromosome. Approximately $25 \%$ of the meningiomas show monosomy 22 as the only aberration in the vast majority of cells. Hypodiploidy without monosomy 22 is very rare. Typically, the loss of chromosome 22 (17-19) is followed by the loss of additional complete chromosomes or parts of them, in particular loss of one chromosomes 6,10, 14, 18, and 19, and partial or complete loss of the short arm of one chromosome 1 (2,20-35). Increasing hypodiploidy is strongly correlated with increasing histological grade.

Cytogenetic models of clonal evolution in tumors have been estimated for various cancer types for which somatic chromosome alterations are known to accumulate over time. These models are important for understanding pathogenic routes on a molecular level. One of the first multi-step models of carcinogenesis has been presented in 1990 by Fearon and 
Vogelstein for colorectal cancers (36). For meningiomas, the first empirical cytogenetic progression model was proposed in 2001 by Zang (35).

Ketter et al (2) recently presented the application of a new mathematical model for tumorigenesis to a large set of 661 cytogenetically characterized meningioma patients, including 53 patients with tumor recurrence. In these models, cancer development is described by mixtures of oncogenetic tree models. Desper et al (37) first introduced single oncogenetic trees, together with an algorithm for estimating the best tree based on subsets of genetic events that correspond to tumor samples. Their single tree model generalizes simpler inflexible path models, allowing several events to happen independently at certain points in the process. In the mixture models estimated by Ketter et al (2), one tree component is restricted to have a star-like topology and represents independence between genetic events. As a consequence, the mixture model has two advantages. First, every genetic pattern can be explained, whereas in the basic models many unexplained patterns must be assigned likelihood zero. Second, the probabilistic framework allows for converting probabilities to times and thus assigning a genetic progression score (GPS) to every tumor sample. All parameters of the mixture model can be estimated with an expectationmaximization-type algorithm (37).

Ketter et al (2) showed that the GPS allows a better assessment of the prognosis of meningiomas than traditional categorical cytogenetic markers. It is strongly predictive for tumor recurrence ( $\mathrm{p}<10^{-6}$ in a Cox regression model) and even provides a further relevant discrimination of high risk and low risk groups within the same WHO grade. As expected, in general, higher GPS values are significantly correlated with higher WHO grades $\left(\mathrm{p}<10^{-10}\right)$. Furthermore, GPS was shown to be siginificantly correlated with tumor location $\left(\mathrm{p}<10^{-8}\right)$, see also Ketter et al (25).

Although more homogeneous than other cancer types, meniningiomas show not only intertumoral but also significant intratumoral heterogeneity. The present analysis of the 661 meningiomas that were previously presented (2) focuses on the clinical relevance of intratumoral heterogeneity. For 221 out of 661 patients (33.4\%), more than one type of cytogenetic pattern was observed in all cells analyzed for the corresponding tumor. The maximum number of different patterns observed in one tumor was 10 , showing considerable heterogeneity. For a tumor with different cytogenetic patterns found in different cells, typically the most frequent pattern is chosen as representative for the genetic state of the tumor. In the present study we demonstrate the benefit of a more detailed analysis in which the pattern associated with the most advanced progression is selected as a marker for tumor progression.

\section{Patients and methods}

Patient population. A retrospective study on 661 meningiomas of patients operated on at the Department of Neurosurgery, University of the Saarland, between January 1973 and April 2005, was performed. Average patient age was 57.3 years (SD \pm 12.8 years). Written informed consent was obtained from each patient participating in the study.

Tumor extirpation. Complete surgical extirpation of the tumor was defined as Simpson grades I and II (38). This corresponds to a macroscopically complete tumor resection with bipolar coagulation of the dura insertion.

Tumor histology. Meningioma grade was assessed by a combined histologic (39) and morphometric approach on routinely H\&E and $\mathrm{Ki}-67 /$ Feulgen stained formalin-fixed, paraffin-embedded tissue sections (29). The 661 meningiomas comprised 465 tumors of WHO grade I, 156 tumors of WHO grade II, and 14 tumors of WHO grade III.

Cell culture and cytogenetic studies. Cell cultures from biopsies and chromosome preparations with Giemsa banding were carried out according to standard procedures (40). More often than not, several changes are present simultaneously. The best approximation to biologic reality may be achieved by subdividing the various clonal aberrations into those that are primary and those that are secondary. Primary aberrations are frequently found as the sole karyotypic abnormalities in cancer and are often specifically associated with particular tumor types. In case of meningiomas the typical primary aberration is the deletion of one chromosome $22(45, \mathrm{XY},-22 ; 45, \mathrm{XX},-22)(35)$. On the other hand secondary aberrations are rarely or never found alone; as the name implies, they develop in cells already carrying a primary abnormality. Typical secondary alterations in meningiomas are deletions of one arm of one chromosome 1 (1p-) or deletions of chromosome $14(17,18,35)$. In addition to this international classification we defined the most frequent and the most advanced clones. In our present study a minimum of 15 mitoses per tumor were evaluated in order to detect intratumoral heterogeneity of cytogenetic aberrations. If in one meningioma 13 metaphases with 45,XX-22 and two metaphases with 44,XX,-22,-1p, were found, we call the 13 metaphases $(45, \mathrm{XX},-22)$ the most frequent clone and the two methaphases (44,XX,-22,-1p) the biologically most advanced clone.

Follow-up. The patients were investigated in the neurosurgical outpatient department of the University of the Saarland, either within routine follow-up or because of the appearance of neurological symptoms. A recurrence was evaluated as new evidence of tumor in CT or NMR after previous complete extirpation (Simpson grades 1 and 2). The Simpson grade 2 was established on the basis of the operation report and the postoperative CT or NMR investigation.

Oncogenetic progression models. Oncogenetic trees describe the ordered accumulation of genetic events, typically chromosomal aberrations, which are assumed to be non-reversible. In a single oncogenetic tree, vertices represent events and edges between vertices represent transitions between these events. Each edge is associated with the probability that the successor event will occur, given the predecessor event has already occurred. In mixtures of oncogenetic trees, several tree components with corresponding mixture weights are estimated (2). Every tree describes the accumulation for a subset of the tumors. The first tree is restricted to have star-like topology, which guarantees that every combination of events has positive likelihood in the mixture model. Every tumor is assigned to the different trees according to the relative likelihood that its corresponding genetic pattern was generated by the trees. An expectation-maximization (EM) algorithm for 


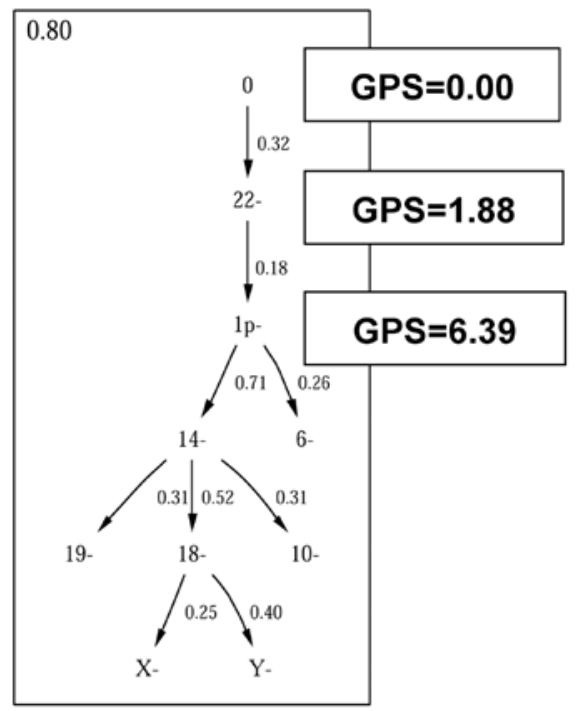

Figure 1. Oncogenetic tree mixture model for the development of menin-giomas. Only the non-trivial component with weight 0.80 is shown. Tree vertices correspond to genetic loss in conventional cytogenetics. Edges are labelled with conditional probabilities. The first two critical steps in the progression model correspond to the GPS values 1.88 (monosomy 22), followed by loss of the short arm of chromosome 1 (GPS value 6.39).

estimating mixtures for oncogenetic trees from a set of genetic patterns was introduced (41).

Genetic progression score (GPS) and corresponding tumor categorization. In oncogenetic trees, the transition probabilities associated with edges can be converted to expected waiting times as shown by Rahnenführer et al (41) for details. Assuming Poisson processes for the occurrence of events, a transition probability $\mathrm{p}$ on a tree edge can be transformed to the waiting time (1-p)/p, multiplied with a scaling factor. The genetic progression score (GPS) of a tumor is then defined as the average waiting time of the corresponding combination of genetic events, given the underlying tree mixture model. A tumor with only early events in the progression model receives a low GPS, and a tumor that exhibits also late events receives a high GPS. The GPS was originally defined for a single genetic pattern associated with every tumor. In the present study, for 221 out of 661 tumor samples, more than one genetic pattern was observed. For this case of multiple patterns, the estimation of mixture models is adapted in the following way. For every tumor, every observed genetic pattern enters the calculation with a weight according to its observed relative frequency in the analyzed cells. This guarantees that all single tumors have equal overall importance in the final estimated mixture model. The estimated mixture model assigns the standard genetic progression score (GPS) to every single genetic pattern (see Fig. 1). Thus, more than one progression score can be assigned to tumors with different genetic patterns observed in different clones (cells). For defining a unique GPS two alternatives are considered. The GPS associated with the most frequently observed genetic pattern is called GPS-frequent (Fig. 2) and the GPS associated with the most advanced genetic pattern is called GPS-advanced. In other words, GPS-advanced is the maximum of all standard GPS values assigned to all genetic patterns observed in a particular tumor.
A

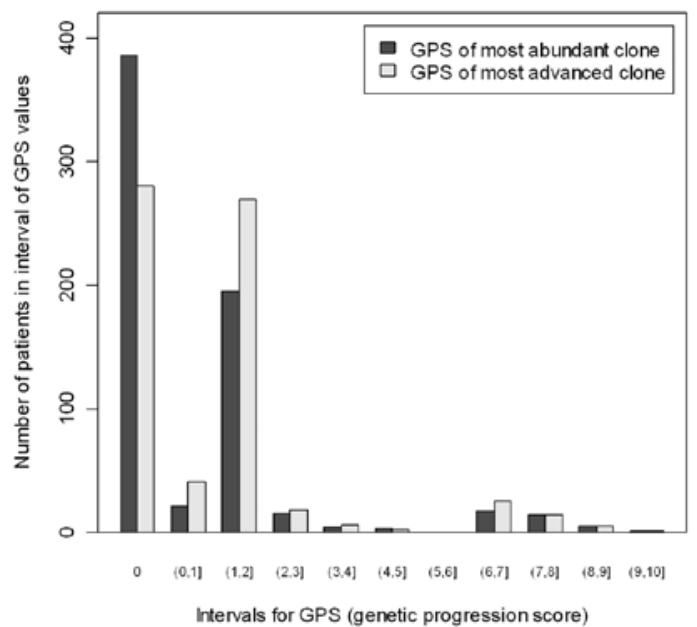

B

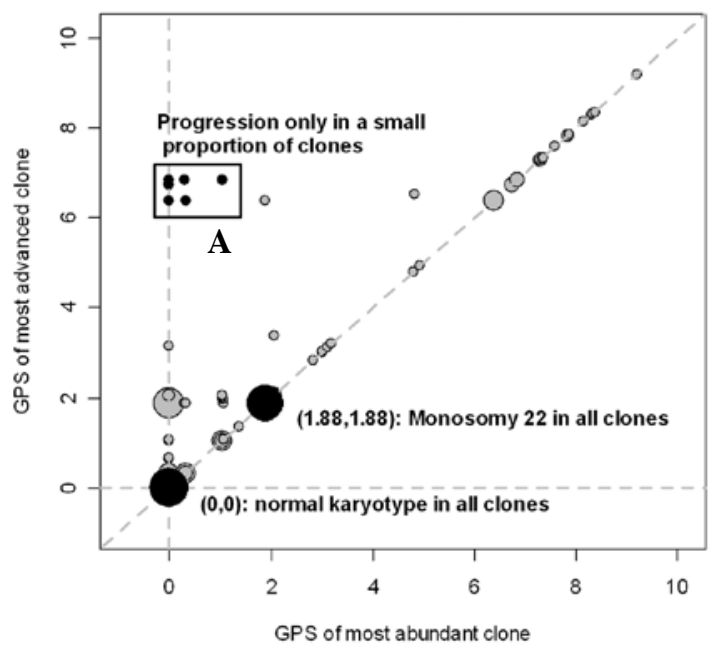

Figure 2. Comparison of genetic progression score (GPS) values for the most frequent and for the most advanced cytogenetic pattern, respectively, observed in 661 meningioma tumors. (A) Histograms of GPS values in bins of width 1 (B) Plot of GPS values of most frequent patterns against GPS values of most advanced patterns. Sizes of circles indicate relative frequencies, black circles indicate the two most frequent combinations $(0,0)$ and $(1.88,1.88)$ and combinations with GPS $<1.88$ for most frequent and GPS $>6.39$ for most advanced pattern, see also Table II for a list of all observed cytogenetic patterns and corresponding frequencies.

In the estimated oncogenetic tree model for meningiomas, the first two decisive steps were loss of chromosome 22 followed by the loss of the short arm of one chromosome 1 , corresponding to a GPS of 1.88 and 6.39, respectively (2). According to these findings, a cytogenetic categorization of meningiomas into three classes named GPS group 0 (GPS <1.88), GPS group 1 (1.88 $\leq$ GPS $<6.39$ ), and GPS group 2 (GPS >6.39) was introduced (2).

\section{Results}

In 224 out of the 661 patients included in the retrospective study, different cytogenetic patterns were detected in the tumor samples emphasizing a considerable cytogenetic heterogeneity in meningiomas.

Of the 661 patients included in our study, 482 were female and 179 were men. The average age of the overall patient population was 57.3 years ( $\mathrm{SD} \pm 12.8$ years). The average age of the 
Table I. Frequencies of genetic aberrations with respect to chromosome losses, taking into account the most frequent cytogenetic pattern observed in every patient (row 1) and the cytogenetically most advanced pattern for every patient (row 2). ${ }^{\mathrm{a}}$

\begin{tabular}{|c|c|c|c|c|c|c|c|c|c|}
\hline Chromosomal aberration & $22-$ & $1 \mathrm{p}-$ & $14-$ & Y- & $\mathrm{X}-$ & $18-$ & $6-$ & $19-$ & $10-$ \\
\hline Frequen & $253(38.3)$ & $50(7.6)$ & $42(6.4)$ & $27(4.1)$ & $30(4.5)$ & $23(3.5)$ & $18(2.7)$ & $13(2.1)$ & $11(1.8)$ \\
\hline Frequency (percentage) advanced & $339(51.3)$ & $60(9.1)$ & $48(7.3)$ & $39(5.9)$ & $37(5.6)$ & $28(4.2)$ & $22(3.3)$ & $19(2.9)$ & $11(1.8)$ \\
\hline
\end{tabular}

${ }^{a}$ Every cell contains the absolute frequency and in brackets the relative frequency (percentage) of the corresponding aberration.

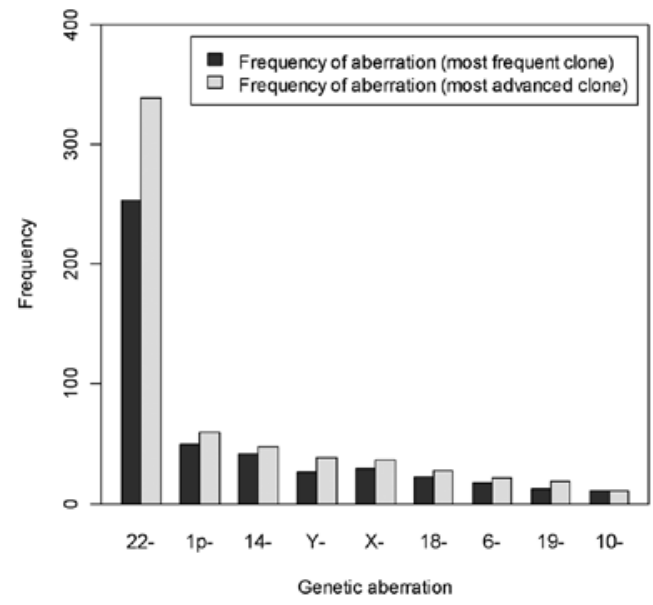

Figure 3. Frequencies of genetic aberrations with respect to chromosome losses, taking into account the most frequent cytogenetic pattern observed in every patient (black) and the cytogenetically most advanced pattern for every patient (grey).

female patients was 57.6 years $(\mathrm{SD} \pm 12.3$ years); average age of the male patients was 56.7 years ( $\mathrm{SD} \pm 14.1$ years). For the 224 patients with intratumoral clonal heterogeneity, the average age was 55.6 years $(\mathrm{SD} \pm 12.5$ years), for the others 57.7 years ( $\mathrm{SD} \pm 12.8$ years). The difference between the age distributions of the two subgroups was not statistically significant (Wilcoxon test, $\mathrm{p}=0.07)$.

The 661 cases investigated comprised 465 common type (WHO grade I), 156 intermediate-type (WHO grade II), and 14 anaplastic meningiomas (WHO grade III). Recurrences were observed in 53 of the cases. This corresponds to a total rate of recurrence of $8.0 \%$ after total tumor extirpation.

Analyzing 661 meningioma biopsies, different karyotypes were detected in 224 of them. In total, 1068 clonal patterns were observed in the 661 tumors. A large number of the detected aberrations were rare mutations only present in a very small subset of the tumors. We thus restrict to the nine most relevant genetic aberrations that were detected in cells of $>10$ patients (incidence of 1.6\%). These most frequent events are losses of chromosomes $6,8,10,14,18,19, \mathrm{X}, \mathrm{Y}$, and loss of the short arm of chromosome 1 . Table I shows the frequencies of losses of these chromosomes for two cases. In the first row, only the most frequent pattern per tumor is considered, in the second row, the pattern with most advanced genetic progression is considered. Loss of chromosome 22 is by far most frequent, followed by loss of chromosomes 1p, 14, X, and Y (Fig. 3).

Taking into account only the reduced set of chromosomal aberrations, in total 1016 different clones were observed in the 661 tumors. In 440 tumors $(66.6 \%)$, only one consistent pattern was detected in all cells, in 140 tumors $(21.2 \%) 2$ patterns, in 52 tumors (7.9\%) 3 patterns, in 16 tumors $(2.4 \%) 4$ patterns, in 7 tumors $(1.1 \%) 5$ patterns, in 4 tumors $(0.6 \%) 6$ patterns and in 1 tumor $(0.2 \%) 7$ patterns and 10 patterns, respectively.

The number of patients belonging to the genetically progression-associated GPS group 2 increases from 37 to 45 , when instead of GPS-frequent the single-cell based GPS-advanced is considered. Since the association of GPS group 2 with increased risk of tumor recurrence was already statistically highly significant for the frequency-based GPS-frequent [Ketter et al (2); Fig. 4A], the following analysis is restricted to the 120 cases
A

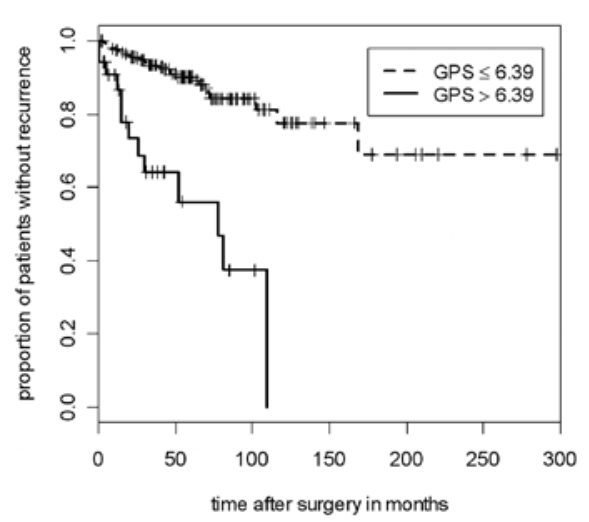

B Patients with several cytogenetic patterns

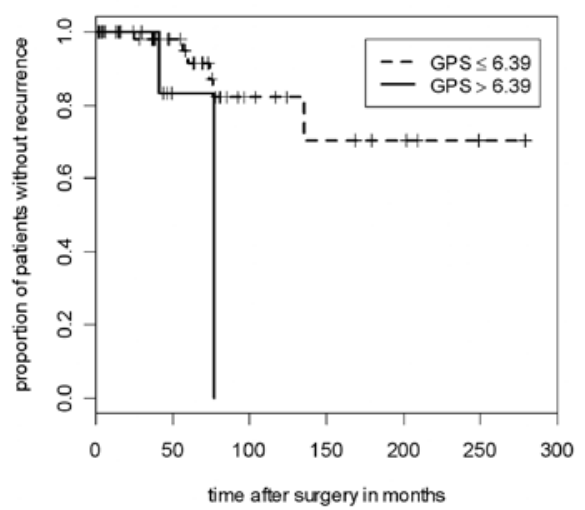

Figure 4. Kaplan-Meier survival curves for time to recurrence of meningioma patients; patients are split into two subgroups according to genetic progression score (GPS $\leq 6.39$ vs. GPS >6.39). (A) Only patients with one consistent cytogenetic pattern observed in all tumor cells are considered. (B) Only patients with intratumoral heterogeneity are considered. 
Table II. Comprehensive list of all 58 cytogenetic patterns observed in 661 meningioma tumors, with corresponding frequencies according to most frequent and most advanced pattern and with corresponding genetic progression score (GPS). ${ }^{\text {a }}$

\begin{tabular}{|c|c|c|c|c|c|c|c|c|c|c|c|c|}
\hline No. & $22-$ & $1 \mathrm{p}-$ & $14-$ & Y- & $X-$ & $18-$ & $6-$ & 19- & 10- & $\begin{array}{l}\text { Frequency } \\
\text { (standard) }\end{array}$ & $\begin{array}{l}\text { Frequency } \\
\text { (advanced) }\end{array}$ & GPS \\
\hline 1 & 0 & 0 & 0 & 0 & 0 & 0 & 0 & 0 & 0 & 386 & 280 & 0.00 \\
\hline 2 & 1 & 0 & 0 & 0 & 0 & 0 & 0 & 0 & 0 & 167 & 241 & 1.88 \\
\hline 3 & 1 & 1 & 0 & 0 & $\mathbf{0}$ & 0 & $\mathbf{0}$ & $\mathbf{0}$ & 0 & 11 & 14 & 6.40 \\
\hline 4 & 0 & 0 & 0 & 1 & 0 & 0 & 0 & 0 & 0 & 10 & 20 & 0.31 \\
\hline 5 & 1 & 0 & 0 & 0 & 1 & 0 & 0 & 0 & 0 & 10 & 9 & 1.04 \\
\hline 6 & 1 & 0 & 1 & 1 & 0 & 0 & 0 & 0 & 0 & 5 & 5 & 2.04 \\
\hline 7 & 1 & 0 & 0 & 1 & 0 & 0 & 0 & 0 & 0 & 5 & 4 & 1.05 \\
\hline 8 & 0 & 0 & 0 & 0 & 1 & 0 & 0 & 0 & 0 & 4 & 9 & 0.30 \\
\hline 9 & 1 & 0 & 1 & 0 & 1 & 0 & 0 & 0 & 0 & 4 & 6 & 2.05 \\
\hline 10 & 0 & 1 & 0 & 0 & 0 & 0 & 0 & 0 & 0 & 4 & 3 & 0.31 \\
\hline 11 & 1 & 1 & 1 & $\mathbf{0}$ & $\mathbf{0}$ & 0 & $\mathbf{0}$ & 0 & 0 & 3 & 6 & 6.85 \\
\hline 12 & 1 & 1 & 1 & 0 & $\mathbf{0}$ & 0 & $\mathbf{0}$ & 0 & 0 & 3 & 6 & 6.85 \\
\hline 13 & 1 & 1 & 0 & $\mathbf{0}$ & $\mathbf{0}$ & 0 & 1 & 0 & 0 & 3 & 4 & 6.75 \\
\hline 14 & 1 & 0 & 1 & 0 & 0 & 0 & 0 & 0 & 0 & 3 & 2 & 1.04 \\
\hline 15 & 1 & 0 & 0 & 0 & 0 & 1 & 0 & 0 & 0 & 3 & 2 & 1.05 \\
\hline 16 & 1 & 0 & 0 & 0 & 0 & 0 & 0 & 1 & 0 & 2 & 3 & 1.03 \\
\hline 17 & 1 & 1 & 1 & 0 & $\mathbf{0}$ & 1 & $\mathbf{0}$ & 0 & 1 & 2 & 2 & 7.84 \\
\hline 18 & 1 & 1 & 1 & $\mathbf{0}$ & $\mathbf{0}$ & 1 & $\mathbf{0}$ & 0 & 0 & 2 & 2 & 7.31 \\
\hline 19 & 1 & 1 & 1 & $\mathbf{0}$ & $\mathbf{0}$ & 0 & 1 & 0 & 0 & 2 & 2 & 7.29 \\
\hline 20 & 1 & 1 & 1 & 0 & $\mathbf{0}$ & 0 & $\mathbf{0}$ & 1 & 0 & 2 & 2 & 7.28 \\
\hline 21 & 1 & 0 & 0 & 0 & 1 & 1 & 0 & 0 & 0 & 2 & 2 & 2.02 \\
\hline 22 & 1 & 0 & 0 & 0 & 1 & 0 & 1 & 0 & 0 & 2 & 2 & 2.01 \\
\hline 23 & 0 & 0 & 0 & 0 & 0 & 0 & 0 & 1 & 0 & 1 & 3 & 0.31 \\
\hline 24 & 1 & 1 & 0 & 0 & 0 & 1 & 0 & 0 & 0 & 1 & 2 & 1.96 \\
\hline 25 & 1 & 0 & 1 & 0 & 0 & 1 & 0 & 0 & 0 & 1 & 2 & 1.98 \\
\hline 26 & 1 & 1 & 1 & 1 & $\mathbf{0}$ & 1 & 1 & 1 & 0 & 1 & 1 & 9.19 \\
\hline 27 & 1 & 1 & 1 & 1 & $\mathbf{0}$ & 1 & 1 & 0 & 0 & 1 & 1 & 8.29 \\
\hline 28 & 1 & 1 & 1 & 1 & $\mathbf{0}$ & 1 & $\mathbf{0}$ & 1 & 0 & 1 & 1 & 8.34 \\
\hline 29 & 1 & 1 & 1 & 1 & $\mathbf{0}$ & 1 & $\mathbf{0}$ & 0 & 1 & 1 & 1 & 8.37 \\
\hline 30 & 1 & 1 & 1 & 1 & $\mathbf{0}$ & 1 & $\mathbf{0}$ & 0 & 0 & 1 & 1 & 7.60 \\
\hline 31 & 1 & 1 & 1 & $\mathbf{0}$ & 1 & 1 & $\mathbf{0}$ & 1 & 0 & 1 & 1 & 8.16 \\
\hline 32 & 1 & 1 & 1 & $\mathbf{0}$ & 1 & 1 & $\mathbf{0}$ & 0 & 1 & 1 & 1 & 8.30 \\
\hline 33 & 1 & 1 & 1 & $\mathbf{0}$ & 1 & 1 & $\mathbf{0}$ & 0 & 0 & 1 & 1 & 7.35 \\
\hline 34 & 1 & 1 & 1 & 0 & 1 & 0 & 1 & 0 & 0 & 1 & 1 & 4.93 \\
\hline 35 & 1 & 1 & 1 & $\mathbf{0}$ & 1 & 0 & $\mathbf{0}$ & 1 & 1 & 1 & 1 & 6.54 \\
\hline 36 & 1 & 1 & 1 & $\mathbf{0}$ & $\mathbf{0}$ & 0 & 1 & 1 & $\mathbf{0}$ & 1 & 1 & 7.82 \\
\hline 37 & 1 & 1 & 1 & $\mathbf{0}$ & $\mathbf{0}$ & 0 & 1 & 0 & 1 & 1 & 1 & 7.82 \\
\hline 38 & 1 & 1 & 1 & $\mathbf{0}$ & $\mathbf{0}$ & 0 & $\mathbf{0}$ & 1 & 1 & 1 & 1 & 7.86 \\
\hline 39 & 1 & 1 & 1 & $\mathbf{0}$ & $\mathbf{0}$ & 0 & $\mathbf{0}$ & 0 & 1 & 1 & 1 & 7.32 \\
\hline 40 & 1 & 1 & 0 & 1 & 0 & 0 & 1 & 0 & 0 & 1 & 1 & 3.20 \\
\hline 41 & 1 & 1 & 0 & 0 & 1 & 1 & 1 & 0 & 0 & 1 & 1 & 4.80 \\
\hline 42 & 1 & 1 & 0 & 0 & 1 & 0 & 0 & 0 & 0 & 1 & 1 & 2.03 \\
\hline 43 & 1 & 1 & 0 & 0 & 0 & 1 & 0 & 1 & 0 & 1 & 1 & 3.01 \\
\hline 44 & 1 & 1 & 0 & 0 & 0 & 1 & 0 & 0 & 1 & 1 & 1 & 2.84 \\
\hline 45 & 1 & 0 & 1 & 1 & 0 & 0 & 0 & 0 & 1 & 1 & 1 & 3.12 \\
\hline 46 & 1 & 0 & 1 & 0 & 0 & 1 & 1 & 0 & 0 & 1 & 1 & 3.02 \\
\hline 47 & 1 & 0 & 0 & 0 & 0 & 0 & 1 & 1 & 0 & 1 & 1 & 1.93 \\
\hline
\end{tabular}


Table II. Continued.

\begin{tabular}{|c|c|c|c|c|c|c|c|c|c|c|c|c|}
\hline No. & $22-$ & $1 p-$ & $14-$ & Y- & X- & $18-$ & $6-$ & 19- & $10-$ & $\begin{array}{l}\text { Frequency } \\
\text { (standard) }\end{array}$ & $\begin{array}{l}\text { Frequency } \\
\text { (advanced) }\end{array}$ & GPS \\
\hline
\end{tabular}

\begin{tabular}{lllllllllllll}
\hline 48 & 1 & 0 & 0 & 0 & 0 & 0 & 1 & 0 & 0 & 1 & 1 & 1.04 \\
49 & 0 & 1 & 0 & 0 & 1 & 0 & 1 & 1 & 1 & 1 & 1 & 1.36 \\
50 & 0 & 0 & 1 & 0 & 0 & 0 & 0 & 0 & 0 & 1 & 1 & 0.30 \\
51 & 0 & 0 & 0 & 0 & 0 & 1 & 0 & 0 & 0 & 0 & 2 & 0.30 \\
52 & 1 & 1 & 1 & 0 & 1 & 0 & 0 & 0 & 0 & 0 & 1 & 3.38 \\
53 & 1 & 0 & 0 & 1 & 0 & 1 & 0 & 1 & 0 & 0 & 1 & 3.16 \\
54 & 1 & 0 & 0 & 1 & 0 & 0 & 1 & 0 & 0 & 0 & 1 & 2.00 \\
55 & 1 & 0 & 0 & 1 & 0 & 0 & 0 & 1 & 0 & 0 & 1 & 2.01 \\
56 & 0 & 1 & 1 & 0 & 0 & 0 & 0 & 0 & 0 & 0 & 1 & 0.64 \\
57 & 0 & 1 & 0 & 0 & 0 & 0 & 1 & 0 & 0 & 0 & 1 & 0.65 \\
58 & 0 & 0 & 0 & 0 & 0 & 1 & 1 & 0 & 0 & 0 & 1 & 0.63 \\
\hline
\end{tabular}

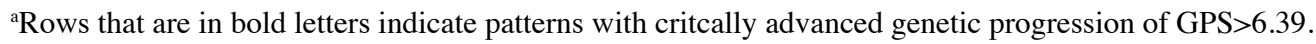

with clonal heterogeneity (97 with complete follow-up information). For these tumors the assignment to GPS groups was as follows. For GPS-frequent 116 tumors belonged to group 0 and 4 to group 1. For GPS-advanced 27 belonged to group 0,85 to group 1 , and 8 to group 2 .

Cox regression analysis was performed in order to measure the influence of genetic progression on risk of tumor recurrence. In a binary model comparing GPS-advanced groups 0 and 1 against GPS-advanced group 2 significant shorter time to recurrence for the genetically advanced patients was observed ( $\mathrm{p}=0.041$ ), see Fig. 4B for corresponding Kaplan-Meier plots. For GPS-advanced as a numerical covariable in the Cox model the respective significance value was $\mathrm{p}=0.054$. For GPS-frequent, the corresponding p-value in the Cox model was 0.95 .

\section{Discussion}

Tumor heterogeneity may be generally defined as variation in the tumor's genotype and/or phenotype (42). Heterogeneity in brain tumors has been identified by using histological description (26), variable expressions of growth factors and their receptors, and cytogenetics (35). Since 1967 cytogenetic analyses have been widely used to understand origin and course of the disease in meningiomas (17). Until now cytogenetic analyses show that numerical and structural chromosome changes with pronounced hypodiploidy, very rarely hyperdiploidy, and especially deletion of the short arm of a chromosome 1, are accompanied by more aggressive biological characteristics (2,20-35).

In 2004 Pfisterer et al (46) addressed genetic heterogeneity in meningiomas. They analyzed eight defined areas of each of 77 meningiomas by fluorescent in situ hybridization using probes localized to chromosome 1, 14 and 22. The authors observed for all three probes that the regional heterogeneity increased according to higher WHO grades. They were able to demonstrate that the detected heterogeneity is important for the biological behavior of meningiomas.

At the same time Sayagués and coworkers (31) investigated the inter- and intratumoral cytogenetic heterogeneity of
125 meningiomas by interphase fluorescence in situ hybridization (iFISH) (31). They used 11 probes for the investigation of numerical chromosome abnormalities and revealed a hypothetical model of an intratumoral aneuploidization pathway for the 11 chromo-somes analysed. At the conventional cytogenetic level Zang (35) proposed a model of clonal evolution in meningiomas. The pool of the cytogenetic findings of 394 meningiomas led to his empirical model of meningioma progression. Although both above mentioned handcrafted models describe very well the genetic findings in meningiomas they are not able to predict the genetic steps which are important for tumor progression and recurrence.

In our previous study we have established a mathematical model for estimating the most likely cytogenetic pathways in meningiomas, based on oncogenetic tree mixture models (2). According to the above-mentioned findings, we were able to define low-risk and high risk-patients according to their GPS group.

Although more homogeneous than other tumor types, meningiomas show considerable intratumoral cytogenetic heterogeneity, particularly in their anaplastic form $(20,21,23,24,29,31,32,43-45)$. These findings raise the question which of the cytogenetic findings is responsible for the further clinical course and the biological behavior of the meningioma.

To clarify the question in the present study we compared the GPS associated with the most frequently observed genetic pattern (GPS-frequent) and the GPS associated with the most advanced genetic pattern (GPS-advanced) (Fig. 2).

It turns out that already single cells with advanced genetic progression indicate earlier recurrence in meningiomas. This underlines the need to analyze a significant number of single tumor cells and to select the cytogenetically most advanced clone for estimating genetic tumor progression.

We admit that it is difficult to introduce this kind of cytogenetic approach into clinical practice. However, it should be feasible to combine histological study and interphase FISH screening for clonal losses of the most frequent chromosome involved. 


\section{Acknowledgments}

This study was supported by the BMBF (grant no. 01GR0453 to J.R. at the Max-Planck-Institute for Informatics) and HomFor (grant no. 68-06). The work at the Max-Planck-Institute for Informatics was performed in the context of the BioSapiens Network of Excellence (EU contact no. LSHG-CT-2003503265).

\section{References}

1. Cushing $\mathrm{H}$ : The cranial hyperostoses produced by meningeal endotheliomas. Arch Neurol Psychiat 8: 139-152, 1922.

2. Ketter R, Urbschat S, Henn W, Feiden W, Beerenwinkel N, Lengauer T, Steudel WI, Zang KD and Rahnenführer J: Application of oncogenetic trees mixtures as a biostatistical model of the clonal cytogenetic evolution of meningiomas. Int J Cancer 121: 1473-1480, 2007.

3. Adegbite AB, Khan MI, Paine KWE and Tan LK: The recurrence of intracranial meningiomas after surgical treatment. J Neurosurg 58: 51-56, 1983.

4. Ayerbe J, Lobato RD, De la Cruz J, Alday R, Rivas JJ, Gómez PA and Cabrera A: Risk factors predicting recurrence in patients operated on for intracranial meningioma. A multivariate analysis Acta Neurochir 141: 921-932, 1999.

5. Beks JWF and De Windt HL: The recurrence of supratentorial meningiomas after surgery. Acta Neurochir (Vienna) 95: 3-5, 1988.

6. Di Meco F, Li KW, Casali C, Ciceri E, Giombini S, Filippini G, Broggi G and Solero CL: Meningiomas invading the superior sagittal sinus: surgical experience in 108 cases. Neurosurgery 55: 1263-1273, 2004

7. Giombini S, Solero CL and Morello G: Late outcome of operations for supratentorial convexity meningiomas. Report on 207 cases. Surg Neurol 22: 588-594, 1984.

8. Giombini S, Solero CL, Lasio G and Morello G: Immediate and late outcome of operations for parasagittal and falx meningiomas: report of 342 cases. Surg Neurol 21: 427-435, 1984.

9. Jellinger K: Histopathological features predicting recurrence of meningiomas after (sub)total resection. Clin Neuropathol 7: 174, 1988.

10. Mahmood A, Caccamo DV, Tomecek FJ and Malik GM: Atypical and malignant meningiomas: a clinicopathological review. Neurosurgery 33: 955-963, 1993.

11. Mahmood A, Qureshi NH and Malik GM: Intracranial menigiomas: Analysis of recurrence after surgical treatment. Acta Neurochir (Vienna) 126:53-58, 1994.

12. McCarthy BJ, Davis FG, Freels S, Surawicz TS, Damek DM, Grutsch J, Meneck HR and Lawser JR: Factors associated with survival in patients with meningioma. J Neurosurg 88: 831-839, 1998.

13. Mirimanoff RO, Dosoretz DE, Linggood RM, Ojemann RG and Martuza RL: Meningioma. Analysis of recurrence and progression following neurosurgical resection. J Neurosurg 62: 18-24, 1985.

14. Philippon J, Cornu PR, Grob R and Rivierez M: Les méningiomes récidivantes. Neurochirurgie 32 (Suppl. 1): 54-62, 1986.

15. Takeuchi H,Kubota T, Kabuto M,Kitai R, Nozaki J and Yamashita J: Prediction of recurrence in histologically benign meningiomas: proliferating cell nuclear antigen and Ki-67 immunohistochemical study. Surg Neurol 48: 501-506, 1997.

16. Yamashita J, Handa $H$ and Iwaki K: Recurrence of intracranial meningiomas, with special reference to radiotherapy. Surg Neurol 14: 33-44, 1980.

17. Zang KD and Singer H: Chromosomal constitution of meningiomas. Nature 216: 84-85, 1967.

18. Zankl $\mathrm{H}$ and Zang KD: Correlation between clinical and cytogenetical data in 180 human meningiomas. Cancer Genet Cytogenet 1: 351-356, 1980 .

19. Zang KD: Cytological and cytogenetical studies on human meningioma. Cancer Genet Cytogenet 6: 249-274, 1982.

20. Bello MJ, De Campos JM, Kusak ME, Vaquero J, Sarasa JL, Pestana A and Rey JA: Allelic loss of $1 \mathrm{p}$ is associated with tumor progression of meningiomas. Genes Chromosomes Cancer 9: 296-298, 1994
21. Espinosa AB, Tabernero MD, Maillo A, Sayagues JM, Ciudad J, Merino M, Alguero MC, Lubombo AM, Sousa P, Santos-Briz A and Orfao A: The cytogenetic relationship between primary and recurrent meningiomas points to the need for new treatment strategies in cases at high risk of relapse. Clin Cancer Res 12: 772-780, 2006

22. Henn W, Cremerius U, Heide G, Lippitz B, Schröder JM, Gilsbach JM, Büll U and Zang KD: Monosomy 1p is correlated with enhanced in vivo glucose metabolism in meningiomas. Cancer Genet Cytogenet 79: 144-148, 1995.

23. Ketter R, Henn W, Niedermayer I, Steilen-Gimbel H, König J, Zang KD and Steudel WI: Predictive value of progression-associated chromosomal aberrations for the prognosis of meningiomas: a retrospective study of 198 cases. J Neurosurg 95: 601-607, 2001.

24. Ketter R, Kim YJ, Storck S, Rahnenführer J, Romeike BF, Steudel WI, Zang KD and Henn W: Hyperdiploidy defines a distinct cytogenetic entity of meningiomas. J Neurooncol 83: 213-221, 2007.

25. Ketter R, Rahnenführer J, Henn W, Kim YJ, Feiden W, Steudel WI, Zang KD and Urbschat S: Correspondence of tumor localization with tumor recurrence and cytogenetic progression in meningiomas. Neurosurgery 62: 61-70, 2008.

26. Kleihues P, Burger PC and Scheithauer BW: The new WHO classification of brain tumors. Brain Pathol 3: 255-268, 1993.

27. Louis DN, Scheithauer BW, Budka H, von Deimling A and Kepes JJ: Meningiomas. In: Pathology and Genetics. Tumors of the Nervous System. Kleihues P and Cavenee WK (eds). IARC, Lyon, 2000.

28. Mueller P,Henn W, Niedermayer I, Ketter R, Feiden W, Steudel WI, Zang KD and Steilen-Gimbel H: Deletion of chromosome 1p and loss of expression of alkaline phosphatase indicate progression of meningiomas. Clin Cancer Res 5: 3569-3577, 1999.

29. Niedermayer I, Feiden W, Henn W, Steilen-Gimbel H, Steudel WI and Zang KD: Loss of alkaline phosphatase activity in meningiomas: a rapid histochemical technique indicating progression-associated deletion of a putative tumor suppressor gene on the distal part of the short arm of chromosome 1. J Neuropathol Exp Neurol 56: 879-886, 1997.

30. Al-Mefty O, Paulo A, Kadri S, Svetlana P, Jeffery RS, Colin Stangeby BS and Husain M: Malignant progression in meningioma: documentation of a series and analysis of cytogenetic findings. J Neurosurg 101: 210-218, 2004.

31. Sayagués JM, Tabernero MD, Má1lo A, Espinosa A, Rasillo A, Díaz P, Ciudad J, LópezA, Merino M, Goncalves JM, Santos-BrizA, Morales F, et al: Intratumoral patterns of clonal evolution in meningiomas as defined by multicolor interphase fluorescence in situ hybridization (FISH). J Mol Diagn 6: 316-325, 2004.

32. Sayagués JM, Tabernero MD, Maillo A, Diaz P, Rasillo A, Bortoluci A, Gomez-Moreta, J, Santos-Briz A, Morales F and Orfao A: Incidence of numerical chromosome aberrations in meningioma tumors as revealed by fluorescence in situ hybridization (FISH) using 10 chromosome-specific probes. Cytometry 50: $153-159,2002$

33. Simon M, von Deimling A, Larson JJ, Wellenreuter R, Kaskel P, Waha A, Warnick RE, Tew JM Jr and Menon AG: Allelic loss on chromosomes 14, 10 and 1 in atypical and malignant meningiomas: a genetic model of meningioma progression. Cancer Res 55: 4696-4701, 1995

34. Weber RG, Boström J, Wolters M, Baudis M, Collins P, Reifenberger G and Lichter P: Analysis of genomic alterations in benign, atypical, and anaplastic meningiomas: Toward a genetic model of meningioma progression. Proc Natl Acad Sci USA 94: 14719-14724, 1997.

35. Zang KD: Meningioma: a cytogenetic model of a complex benign human tumor, including data on 394 karyotyped cases. Cytogenet Cell Genet 93: 207-220, 2001.

36. Fearon $\mathrm{E}$ and Vogelstein B: A genetic model for colorectal tumorigenesis. Cell 61: 759-767, 1990.

37. Desper R, Jiang F, Kallioniemi OP, Moch H, Papadimitriou CH and Schaffer AA: Inferring tree models for oncogenesis from comparative genome hybridization data. J Comput Biol 6: 37-51, 1999.

38. Simpson D: The recurrence of intracranial meningiomas after surgical treatment. J Neurol Neurosurg Psychiatry 20: 22-39, 1957.

39. Kolles H, Niedermayer I, Schmitt Ch, Henn W, Feld R, Steudel WI, Zang KD and Feiden W: Triple approach for diagnosis and grading of meningiomas: histology, morphometry of Ki-67/ Feulgen stainings, and cytogenetics. Acta Neurochir (Vienna) 137: 174-181, 1995. 
40. Limon J, Dal-Cin P and Sandberg AA: Application of long-term collagenase disaggregation for the cytogenetic analysis of human solid tumors. Cancer Genet Cytogenet 23: 305-313, 1986.

41. Rahnenführer R, Beerenwinkel N, Schulz WA, Hartmann C, von Deimling A, Wullich B and Lengauer T: Estimating cancer survival and clinical outcome based on genetic tumor progession scores. Bioinformatics 21: 2438-2446, 2005.

42. Coons SW and Johnson PC: Regional heterogeneity in the DNA content of human gliomas. Cancer 72: 3052-3060, 1993.

43. Menon GM, Rutter JL, von Sattel JP, Synder H, Murdoch C, Blumenfeld A, Martuza RL, von Deimling A, Gusella JF and Houseal TW: Frequent loss of chromosome 14 in atypical and malignant meningioma: identification of a putative 'tumor progression' locus. Oncogene 14: 611-616, 1997.
44. Perry A, Stafford SL, Scheidhauer BW, Suman VJ and Lohse CM: Meningioma grading: an analysis of histologic parameters. Am J Surg Pathol 21: 1455-1465, 1997.

45. Perry A, Gutmann DH and Reifenberger G: Molecular pathogenesis of meningiomas. J Neurooncol 70: 183-302, 2004.

46. Pfisterer WK, Hank NC, Preul MC, Hendricks WP, Pueschel J, Coons SW and Scheck AC: Diagnostic and prognostic significance of genetic regional heterogeneity in meningiomas. Neurooncology 6: 290-299, 2004. 